\title{
THE PURPLE COLOR REACTION GIVEN BY DIPHENYLAMINE REAGENT. I. WITH NORMAL AND RHEUMATIC FEVER SERA ${ }^{1}$
}

\author{
By WASHINGTON AYALA,2 LUCILE V. MOORE, AND EUGENE L. HESS
}

\begin{abstract}
(From the Rheumatic Fever Research Institute, Northwestern University Medical School, Chicago, Ill.)
\end{abstract}

(Submitted for publication February 2, 1951; accepted May 7, 1951)

Niazi and State (1) recently reported that when human serum was heated with the diphenylamine reagent of Dische $(2,3)$ a purple color developed. They also observed that in certain disease states, e.g., carcinoma, pulmonary tuberculosis and rheumatic fever, the purple color reaction was of considerably greater intensity than in the serum of normal persons. We observed this color reaction when testing saline extracts of bovine tonsils for the presence of desoxyribonucleic acids using the Dische diphenylamine reagent. Subsequent fractionation of the tonsil extracts revealed that the substance which gave the purple color reaction with diphenylamine was a mucoprotein with an unusually low isoelectric point $\left(\mathrm{pI}_{\mathrm{e}}<2.0\right)$ (4). In confirmation of certain findings of Niazi and State (1) we have observed that serum from rheumatic fever and rheumatoid arthritis patients gives a color of greater intensity than does the serum from normal individuals.

The resulting purple solution has one absorption band in the visible spectrum, with a maximum at $530 \mathrm{~m} \mu$. This same absorption band is present when either serum or our purified mucoprotein from beef tonsils (4) is tested.

In this report we shall present observations with respect to the reaction, and suggest modifications in technique. We have applied the method to rheumatic fever sera, the results of which are included.

\section{Conditions of the reaction}

The addition of Dische's reagent ${ }^{3}$ directly to serum produces upon heating a turbid colored solu-

\footnotetext{
1 Supported in part by grants from the United States Public Health Service and from the Chicago Heart Association.

2 Present address: Facultad de Quimica y Farmacia, Montevideo, Uruguay.

${ }^{3}$ Composition of the reagent : glacial acetic acid $100 \mathrm{ml}$., conc. sulfuric acid $2.75 \mathrm{ml}$, diphenylamine $1 \mathrm{gm}$.
}

tion unsuitable for colorimetric readings. When serum proteins are precipitated with $20 \%$ trichloroacetic acid solution, the purple color reaction is present in the acid hydrolyzate obtained from the precipitate and absent in the filtrate. The moiety giving the purple color is dialyzable from serum only after acid or alkaline hydrolysis. In the procedure described by Niazi and State (1), the proteins are precipitated from serum with a $20 \%$ trichloroacetic acid solution, the supernatant discarded, the precipitate hydrolyzed with a $5 \%$ trichloroacetic acid solution, and the clear supernatant obtained after centrifugation is tested with the diphenylamine reagent. Since the $20 \%$ trichloroacetic acid filtrate from serum does not contain any interfering substance we have found it satisfactory to hydrolyze the serum directly. A study of the hydrolysis step shows that the intensity of the purple color reaction increases with time up to 20 minutes and then decreases slowly and becomes negative after several hours. For this reason we have adopted 20 minutes as a standard time of hydrolysis.

The time of heating the serum hydrolyzate and the reagent is another important factor in the intensity of the color produced. A plot of color intensity (in terms of optical density at $530 \mathrm{~m} \mu$ ) against time of heating shows a rapid increase with time up to two hours, after which the rate of increase is slight. When the heating is continued, the purple color shifts to blue (clearly noticeable at two hours) and the absorption curve develops a new band with a maximum at $650 \mathrm{~m} \mu$ in addition to the one at $530 \mathrm{~m} \mu$. The variation in the shape of the absorption curves with time of heating is presented in Figure 1. We have selected 30 minutes as a standard time of heating; at this time an intense purple color is obtained with little interference from the blue band, as can be seen in Figure 1. 


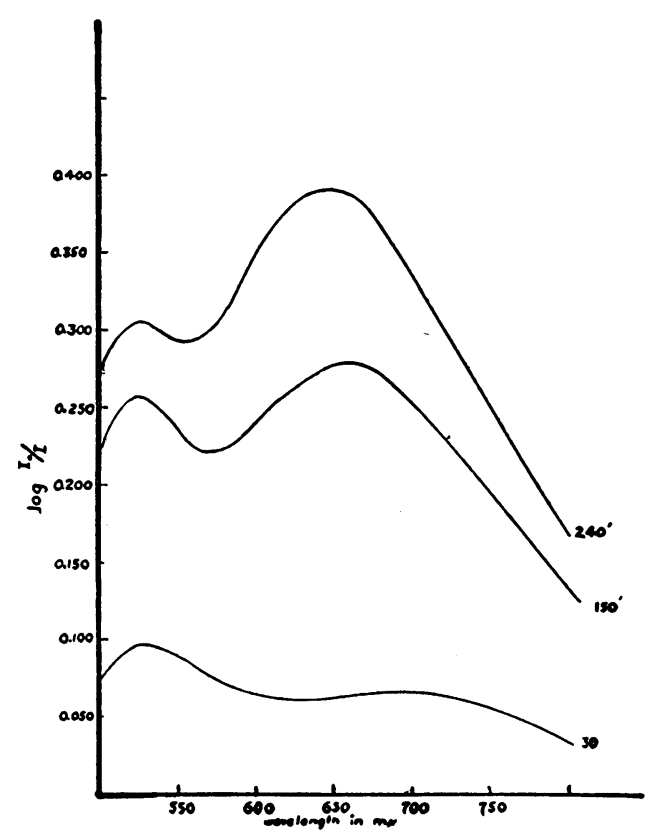

Fig. 1. Variation in the Absorption Spectrum with the Time of Heating the Reaction

Curves are shown for 30,150 , and 240 minutes of heating in a boiling water bath. Absorption measurements were made on a Model DU Beckman Spectrophotometer.

Varying the concentration of diphenylamine in the reagent between 0.5 and $1.5 \%$ has little effect upon the color development. We have maintained the $1 \%$ concentration of the original Dische reagent. On the other hand, the sulfuric acid concentration of the reagent has a marked influence on the intensity of the color, the intensity increasing as the acid concentration increases up to $10 \%$ in volume, where the curve becomes asymptotic. Therefore, replacement of the $2.75 \mathrm{ml}$. of concentrated sulfuric acid used in the original Dische formula with $10 \mathrm{ml}$. is useful in detecting the moiety when it is present in low concentrations. In this report we shall call the reagent containing $10 \mathrm{ml}$. of concentrated sulfuric acid "sensitive reagent", "and the one prepared according to Dische's formula "standard reagent."

It is important to note that the absorption curves obtained from serum using either standard or sensitive reagent have the same general shape provided a standard time of heating of 30 minutes is

\footnotetext{
4 Composition of sensitive reagent: glacial acetic acid $90 \mathrm{ml}$., conc. sulfuric acid $10 \mathrm{ml}$, diphenylamine $1 \mathrm{gm}$.
}

employed in both cases. This can be seen in Figure 2.

Using a Model DU Beckman Spectrophotometer we have determined that the color reaction obeys Beer's Law over the range of optical densities with which we have worked. Measurements included in Table I and in Figure 3 were made with a Model 6A Coleman Spectrophotometer. With this instrument when the optical density measured was greater than 0.650 it was customary to dilute the sample and multiply the reading obtained with the diluted sample by the appropriate dilution factor.

\section{Suggested procedures}

On the basis of these findings, the following procedures are recommended:

a) Macro procedure: Two ml. of the sample (plasma or serum), are placed in a $25 \times 150 \mathrm{~mm}$. test tube, and $10 \mathrm{ml}$. of a $5 \%$ trichloroacetic acid solution are added slowly with gentle shaking in order to obtain fine floccules of precipitate. The tube is then placed in a boiling water bath for exactly 20 minutes and immediately cooled by immersion in ice water. The tubes are stoppered during the hydrolysis with a perforated rubber stopper fitted with $20 \mathrm{~cm}$. long glass tubing which acts as a condenser. The hydrolyzate is filtered, and $1.5 \mathrm{ml}$. of the clear filtrate is transferred to a $18 \times 150 \mathrm{~mm}$. o.d. test tube to which are added $3 \mathrm{ml}$. of standard reagent. The tube is then immersed in a boiling water bath for exactly $30 \mathrm{~min}$ utes. After removal from the boiling water the tube is cooled in ice water and allowed to come to room temperature. The color intensity is stable for several hours at room temperature. The optical density was read in a Model 6A Coleman Spectrophotometer at $530 \mathrm{~m} \mu$ in the $18 \times 150 \mathrm{~mm}$. test tube in which the color was developed. A large number of $18 \times 150 \mathrm{~mm}$. Pyrex test tubes were examined for uniform optical properties. Tubes were selected which were uniform to \pm 0.005 optical density units at an optical density of 0.300 and at a wavelength of $\mathbf{5 3 0}$ $\mathrm{m} \mu$. This is well within the standard error of the method. The adapter on the Model 6A Coleman Spectrophotometer was modified by reducing the vertical light path to $15 \mathrm{~mm}$. in order to accommodate a $4.5 \mathrm{ml}$. sample.

Two blanks are required. One blank consists of $5 \%$ trichloroacetic acid and standard reagent in proportions corresponding to those used for the reaction. This blank is used to establish the zero optical density setting of the spectrophotometer. The second blank consists of $1.5 \mathrm{ml}$. of serum hydrolyzate and $3.0 \mathrm{ml}$. of acetic sulfuric acid mixture ${ }^{5}$ without diphenylamine. The second blank must be prepared separately for each serum sample. The optical density of this blank is subtracted from the corresponding serum sample giving the purple color reaction.

Composition : glacial acetic acid $100 \mathrm{ml}$., conc. sulfuric acid $2.75 \mathrm{ml}$. 


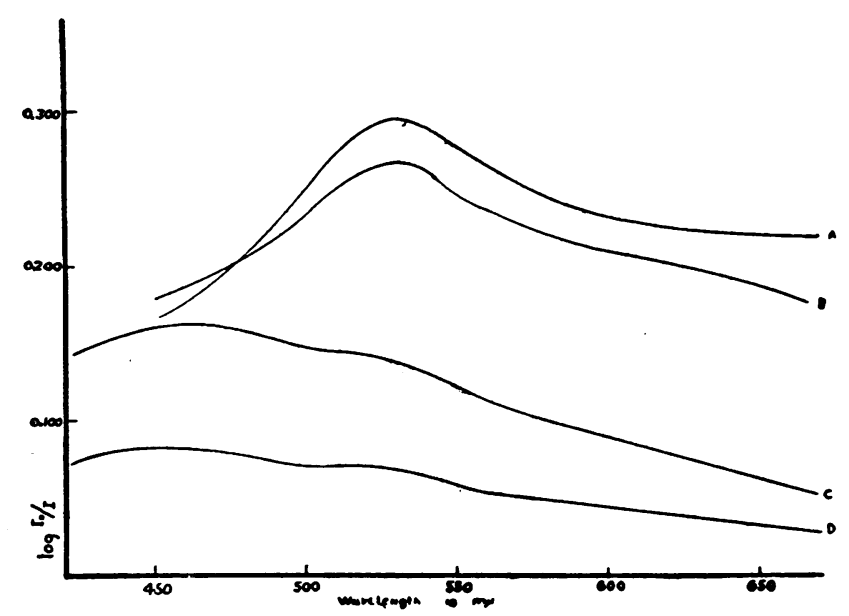

Fig. 2. Comparison of the Absorption Curves Obtained USing the "Sensittve" and the "Standard" Reagents and Mixtures

Measurements made on a Model DU Beckman Spectrophotometer.
A. with sensitive reagent
B. with standard reagent
C. with sensitive mixture *
D. with standard mixture *

* Acetic and sulfuric acids in the proportions used in the reagents but without diphenylamine.

This furnishes the corrected optical density of the purple color determination.

A mixture of sulfuric and acetic acids in the proportions used in the reagent, when added to serum hydrolyzate, gives a light brown color with a broad absorption band as is seen in Figure 2. The sulfuric acid in the mixture causes this color development. Since the intensity of this color varies with individual serum samples it must be subtracted from the measured optical density of the purple color reaction.

b) Semimicro procedure: For small serum samples, the following procedure is suggested: To $0.2 \mathrm{ml}$. of the sample (serum or plasma) in an $18 \times 150 \mathrm{ml}$. o.d. test tube add $5 \mathrm{ml}$. of a $5 \%$ trichloroacetic acid solution, slowly and with shaking. The method described in the macro procedure above is followed with one exception. In the micro technique "sensitive reagent" is used instead of standard reagent, and "sensitive mixture" 6 replaces the standard mixture.

\section{Reproducibility of the results}

The arithmetic mean of the optical densities of 20 samples of the same serum using the macro procedure was 0.440 with a standard deviation of 0.018 . The coefficient of variation was found to be

6 Composition : glacial acetic acid $90 \mathrm{ml}$., conc. sulfuric acid $10 \mathrm{ml}$.
$4.09 \%$. We have expressed the results of the reaction in terms of optical density at $530 \mathrm{~m} \mu$ since the molecular structure of the substances responsible for the purple color development in serum are as yet unknown. Evidence to be discussed elsewhere (5) suggests that the purple color development is due to a carbohydrate moiety bound mainly, if not exclusively, to the serum mucoproteins, and found in the alpha globulin fraction of serum. The arithmetic average of the optical density of serum samples from 17 normal adults (male and female) using the macro procedure, is 0.374 , with a standard deviation of 0.041 .

We have established the normal range of optical densities by using twice the standard deviation on either side of the arithmetic mean. The normal range of optical density is found to be from 0.292 to 0.456 . Since our procedure differs from that used by Niazi and State (1), our values are not directly comparable. Nevertheless, the values obtained by Niazi and State differ but slightly from the values reported above.

The arithmetic average of the optical density of serum samples from 14 normal adults (male and 
female) using the semimicro procedure, is 0.332 , with a standard deviation of 0.022 . The normal range of values thus becomes 0.288 to 0.376 using this procedure.

\section{Application of the method to rheumatic fever}

The plasma or serum of rheumatic fever patients has been tested using the macro procedure previously described. We find that both serum and plasma give the same color intensity within the experimental error of the method.

Blood samples were collected from patients, either in the fasting or post-prandial state, on the wards of the Children's Memorial Hospital ${ }^{7}$ and from ambulatory patients attending the Bridgeport Clinics. ${ }^{8}$ When serum was used this was centrifuged from the clot as soon as possible and the reaction was carried out immediately. If this was not practicable, samples were stored at $5^{\circ} \mathrm{C}$.; storage at this temperature for as long as six days does not affect the color yield. When plasma was used, heparinized blood samples were collected and centrifuged as soon as possible. Heparin gives a negative color test and does not interfere with the reaction.

We have tested a total of 107 samples from rheumatic patients in different stages of the disease. The results are recorded in Table $I$. The figures in Table I show that in acutely ill patients, the mean values of the reaction are significantly high (62.8\% higher than the normal mean).

Figure 3 represents graphically the distribution of values found in the clinically active group of

TABLE I

Purple color reaction values found in sera of rheumatic fever patients (in terms of optical density at $530 \mathrm{m \mu}$ )

(Macro procedure)

\begin{tabular}{c|l|c|c}
\hline \hline $\begin{array}{c}\text { Number } \\
\text { of } \\
\text { cases }\end{array}$ & Stage & $\begin{array}{c}\text { Arithmetic } \\
\text { mean of } \\
\text { the group }\end{array}$ & $\begin{array}{c}\text { Per cent } \\
\text { increase } \\
\text { over } \\
\text { normal } \\
\text { mean }\end{array}$ \\
\hline 40 & Clinically acute cases & 0.609 & 62.8 \\
33 & Cases with only mild activity & 0.530 & 41.7 \\
34 & Inactive cases & 0.420 & 12.3 \\
\hline
\end{tabular}

7 We are indebted to the Children's Memorial Hospital for providing these samples.

8 Clinics for rheumatics maintained by the Rheumatic Fever Research Institute at the Bridgeport Salvation Army Dispensary.

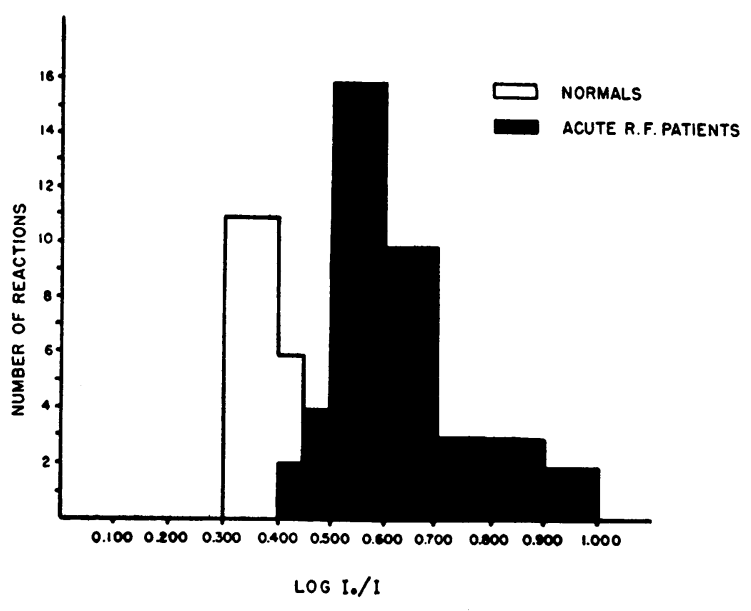

Fig. 3. Distribution of Purple Color Values of Normal and Rheumatic Sera, Using the Macro ProCEDURE Described

cases, around the arithmetical mean of the group. For comparison the values of normals are similarly represented.

The second group in Table I includes patients who had no clinical symptoms of rheumatic activity but still had slightly elevated temperatures or had sedimentation rates above normal. In this group also, the arithmetical mean of the values was significantly higher than normal levels but in a lower range than the first group.

The third group is made up of quiescent rheumatic subjects. The arithmetical mean of this group, although above the normal mean (12.3\%), fell within the normal range.

The purple color reaction appears to be significantly elevated during acute rheumatic fever, to decrease with lessening of the rheumatic activity and to return to normal upon recovery. Furthermore, the intensity of the reaction appears to parallel the erythrocyte sedimentation rate except where the E.S.R. was depressed during congestive heart failure. Under these conditions the purple color reaction parallels rheumatic activity.

\section{SUMMARY}

1. The conditions of a reaction between serum and diphenylamine reagent have been studied. Based upon these studies a simplified procedure for carrying out the reaction is recommended. With the procedure the arithmetic mean of the optical densities for normal human serum is 0.374 . 
The standard deviation is 0.041 , and the range of values for normal human serum is shown to be 0.292 to 0.456 .

The composition of a more sensitive reagent is also given. With this sensitive reagent it is possible to make determinations with $0.2 \mathrm{ml}$. of serum or plasma. The arithmetic mean of the optical densities for normal human serum is 0.332 in the semimicro procedure. The standard deviation is 0.022 and the range of values for normal human serum is 0.288 to 0.376 .

2. One hundred and seven blood samples from patients in different stages of rheumatic fever have been tested with the macro procedure. The purple color level in serum or plasma was found to be significantly elevated during rheumatic activity. However, in inactive rheumatic subjects the mean of the group was found to be within normal range. Serial determinations with this test may be used as an adjunct to current methods for following the course of rheumatic activity.

\section{REFERENCES}

1. Niazi, S., and State, D., The diphenylamine reaction of human serum. Cancer Research, 1948, 8, 653.

2. Dische, Z., Uber Microbestimmung der Kohlehydrate in tierschen Organen und im Blut mit Hilfe charakteristischer Farberreaction. I. Mikrochemie, 1929, 7, 33.

3. Dische, Z., Uber einige neu charakteristische Farbereaktionen der Thymonulkeinsaure und eine Mikromethode zur Bestimmung derselben in tierschen Organen mit Hilfe dieser Reaktionen. Mikrochemie, 1930, 8, 4.

4. Hess, E. L., Ayala, W., Cobure, A., and Herranen, A., The separation and properties of a mucoprotein from beef tonsils. In preparation.

5. Hess, E. L., and Ayala, W., Structural features of substances giving the purple color reaction with diphenylamine reagent. In preparation. 